\title{
Isolation by distance in a population of a small land snail Trochoidea geyeri: evidence from direct and indirect methods
}

\author{
MARKUS PFENNINGER, ANDREAS BAHL AND BRUNO STREIT \\ Abteilung Ökologie \& Evolution, Fachbereich Biologie, Johann Wolfgang Goethe-Universität, Siesmayerstr. 70, D-60054 \\ Frankfurt am Main, Germany
}

\begin{abstract}
SUMMARY
Population structure was estimated in a continuous population of a small land snail (Trochoidea geyeri). Mark-recapture experiments and randomly amplified polymorphic DNA analyses indicate that the population structure can be described by the isolation by distance model of Wright (1946). Estimates of density and dispersal suggest a neighbourhood size of 70-208 individuals on an area of $13-21 \mathrm{~m}^{2}$. A principal component analysis of the randomly amplified polymorphic DNA data reveals clinal variation of genetic composition across the population, as predicted by the neighbourhood concept. An analysis of molecular variance indicates substantial genetic structuring. Comparisons of the genetic distances, expressed as euclidean distances among individuals, versus the geographic distance between sampling sites yield a highly significant positive correlation (Mantel test: $r=0.567, p<0.0001$ ). The revealed pattern of populational subdivision on a microgeographic scale seems to be one of the principal processes generating and maintaining genetic diversity within populations of small land gastropods.
\end{abstract}

\section{INTRODUGTION}

Revealing the mechanisms responsible for the creation and maintenance of genetic variation within populations is one main aim in population genetics, because genetic variation is indispensable for evolution to proceed (Wright 1932; Lewontin 1974). Genetic variation often can be attributed to factors responsible for generating population structure (Wright 1978), such as genetic drift (see, for example, Lacy 1987), mating system (see, for example, Jarne \& Städler 1995) or behaviour (see, for example, Bowen et al. 1992). Population structure can be assessed by direct (field observation) or indirect (molecular genetic) methods (Slatkin 1987). Until now, only a few studies exist combining both direct and indirect methods (Eguiarte et al. 1993; Schilthuizen \& Lombarts 1994; Castillo 1994; Johnson \& Black 1995), though the integration of both approaches promises to reveal interactions of evolutionary forces that shape the structure of natural populations (Slatkin 1987).

In cases where the area of continuous distribution of a population by far exceeds the dispersal ability of individuals, random mating cannot be assumed over the whole population. The population structure can then be dominated by the interaction of population density and dispersal. Each individual in such a population has only a limited number of potential parents, the 'neighbourhood', a concept introduced by Wright (1946). The neighbourhood is associated with an area within a population where random mating is possible. The expected genetic population structure can be calculated from the neighbourhood size and can be described as 'isolation by distance' within the population. Wright (1951) saw this concept as a way to explain genetic variability under a uniform selective regime. Because of their low dispersal ability, the neighbourhood concept may be especially appropriate for describing the population structure of land snails (Greenwood 1974; Crook 1980; Cowie 1984).

In this study, we will focus on a terrestrial pulmonate gastropod, Trochoidea geyeri (Soós 1926). T. geyeri is a small (5-8 $\mathrm{mm}$ diameter), annual helicid species in the subfamily Helicellinae. It inhabits calcareous soils with a low degree of vegetational cover of dry grassland. We observed active movement only during cool and humid weather conditions. Matings can be observed in autumn, before hibernation. The eggs are deposited in the soil a few weeks after emergence in spring. Our lifehistory observations indicate that $T$. geyeri might be a poor disperser (Pfenninger \& Bahl 1995; Bahl et al. 1996). Therefore, the species is a likely candidate for a neighbourhood population structure even on microgeographic scales.

In the present study, we integrate both direct and indirect methods for the assessment of population structure. The role of dispersal and density for shaping the population structure is examined with markrecapture studies and density measures, whereas the spatial pattern of genetic variation is studied using randomly amplified polymorphic DNA (RAPD; Williams et al. 1990). 


\section{MATERIALS AND METHODS}

\section{(a) Research area}

The research area is an abandoned vineyard with an approximate size of $40000 \mathrm{~m}^{2}$, now covered with dry open grassland situated on a limestone hill near Schlüchtern, central Germany. The area is slightly structured by bushes and hedges, marking the boundaries between former vineyards, but open enough to consider the suitable habitat for the snail population to be continuous (see figure 1).

\section{(b) Direct method}

A marked patch, $5 \mathrm{~m} \times 5 \mathrm{~m}$ in size with a $1 \mathrm{~m}$ grid, was set up in the centre of the vineyard (for details see Pfenninger \& Bahl 1995). The marked patch was searched carefully for living $T$. geyeri on average every 15 th day, except for the time of hibernation. All $T$. geyeri found on the patch for the first time were marked individually. Their position relative to the grid was recorded on a map and they were released immediately at the original position. The position of previously marked snails was recorded in the same way. Distances dispersed between two records were measured as straight lines. If an individual died between two findings, dispersal distance was not considered. Orientation of movement was analysed based on sectors of $45^{\circ}$. The recording of movement was terminated at the end of July, when only dead adult snails were found.

A total of 24 randomly chosen quadrats $(1 \mathrm{~m} \times 1 \mathrm{~m})$ were sampled at the end of March 1995 within the vineyard. All vegetation was removed to the blank soil and searched for living T. geyeri. Additionally, within each quadrat, three soil samples of $35 \mathrm{~cm} \times 35 \mathrm{~cm}$ each were cut out $5 \mathrm{~cm}$ in depth and searched thoroughly for living snails. Information about patterns of distribution during mark-recapture experiments was obtained by means of an index of dispersion (Southwood 1978). Tests for aggregations greater than sample unit of $1 \mathrm{~m}^{2}$ were done by means of the Iwao-index (Iwao 1972).

Computer simulation of a random-movement model was used to estimate dispersal over longer periods. Random movement can be assumed when: (i) no direction is preferred; (ii) direction of moves is independent of previous moves; and (iii) distance moved by an individual is a random variate of an exponential distribution (Pielou 1969). To

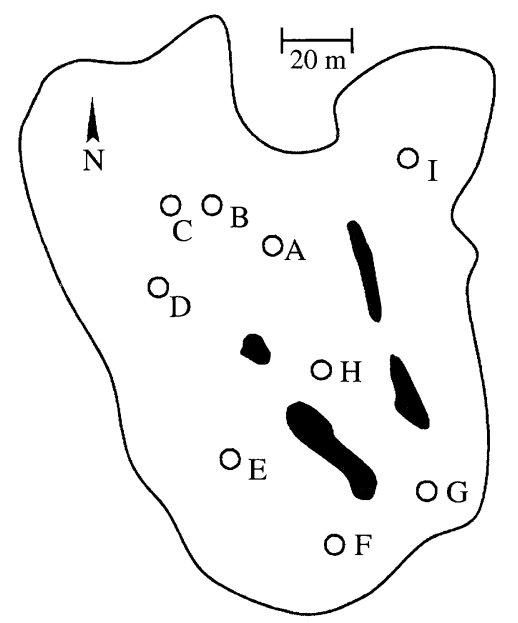

Figure 1. Location of the nine sampling sites (A-I) for molecular genetic analysis of the population structure. The entire area is a former vineyard. At each site, seven to nine snails were sampled. The shaded areas represent unsuitable habitat for Trochoidea geyeri (bushes and hedges). simulate dispersal, random variates of the empirically determined exponential function of dispersal per $15 \mathrm{~d}$ were assigned to a random direction. Distances dispersed were calculated as straight lines between the starting point and the point reached after a given time. For each multiple of a 15day period up to $210 \mathrm{~d}$, the simulation was repeated 1000 times.

Wright (1946) calculated the neighbourhood size $N$ for a continuously distributed population of randomly mating simultaneous hermaphrodites in a two-dimensional habitat as

$N=4 \pi \sigma^{2} d$,

with $\sigma^{2}$ the variance of dispersal along a single axis from parents relative to their offspring at the same developmental stage and $d$ as the density of breeding individuals. Following Greenwood (1976), variance of dispersal along a single axis was calculated as half the variance of dispersal in all directions. The time period for dispersal considered for the calculation of neighbourhood size $(120-150 \mathrm{~d})$ is equivalent to the period from September, when young snails reach a size that allows substantial movement, to April-May, when eggs are deposited in the soil, excluding the time of hibernation. We calculated the neighbourhood size for the mean \pm s.d. of population densities. Transformation of the neighbourhood formula shows that a neighbourhood is associated with an area of a circle with a radius of $\sqrt{2 \sigma}$.

\section{(c) Indirect method}

For the molecular genetic analysis, a total of 75 snails were sampled from nine randomly chosen sites, as illustrated in figure 1. At each site, seven to nine snails were sampled within the calculated neighbourhood area.

DNA from snail tissue was extracted following the protocol of Bahl \& Pfenninger (1996). For details of the RAPD procedure see Pfenninger et al. (1995). We applied 5 primer (OPAB01, OPC15, OPC16, OPP05, OPP11, Operon Technologies Inc.). Bands were scored only when they could be reproduced with two different DNA concentrations in two amplifications. For statistical analyses, the data were transformed into a binary matrix, where presence of a band was coded as 1 and absence as 0 .

We subjected the presence-absence matrix to a principal component analysis (PCA). This statistical technique achieves an ordination of the individuals according to the presence or absence of certain bands along principal component axes (Manly 1994). These principal components are uncorrelated to each other and account, in decreasing order, for portions of the total RAPD variation. This has the advantage of taking into account 'typical' bands correlated to sampling sites.

Population structure was tested by an analysis of molecular variance (AMOVA; Excoffier et al. 1992). AMOVA calculates standard variance components and correlation measures, referred to as $\phi$-statistics, for a maximum of three hierarchical levels of populational subdivision. The significance of the observed variance components and $\phi$-values was tested using a random permutation procedure on the original data matrix. For this analysis, the $0 / 1$ matrix was transformed into a squared euclidean distance matrix between all 75 individuals. The squared euclidean distance between two binary vectors equals the absolute number of differences of the vectors, i.e. in terms of RAPD markers, the number of bands not shared between two individuals. The analyses were done with winamova vers. 1.55 (L. Excoffier).

To determine whether the genetic structure of the population can be described by the isolation by distance model, we compared the corresponding matrices of interindividual euclidean distances and geographical distances 
between the sampling sites of individuals using a Mantel test (Mantel 1967). PCA and the Mantel test were done with NTSYS-pc, release 1.60 (Applied Biostatistics Inc. 1990)

\section{RESULTS}

\section{(a) Direct method}

During the whole sampling period, a total of 630 snails were marked, $113(17.9 \%)$ of which were found at least once again. It was possible to record 146 movements. No direction of movement was preferred $\left(\chi^{2}=1.761 ; n=146 ; p=0.97 ;\right.$ comparison with a uniform distribution). Directions of second moves were independent from first moves $\left(\chi^{2}=1.333 ; n=36 ; p=\right.$ 0.99 ; comparison of deviation from first move with a uniform distribution). Distances covered within $15 \mathrm{~d}$ ranged from 0 to $4.23 \mathrm{~m}$ with a mean of $0.86 \pm 0.79 \mathrm{~m}$ (mean \pm s.d., $n=146$ ). The frequency distribution of dispersal distances fitted a function with exponential decay $\left(y=66.37 \mathrm{e}^{(-1.13 x)}\right)$. Random movement can thus be assumed.

This exponential function was used to do the computer simulation of long time dispersal. Simulated average dispersal in a two-dimensional habitat increased from $0.86 \mathrm{~m}$ in $15 \mathrm{~d}$ to $3.90 \mathrm{~m}$ in $210 \mathrm{~d}$. Average distance dispersed after 120 and $150 \mathrm{~d}$ was $2.94 \mathrm{~m}$ and $3.22 \mathrm{~m}$, respectively. Maximum distance dispersed after $210 \mathrm{~d}$ was $13.09 \mathrm{~m}$.

The quadrat counts on the surface gave an estimate of $4.25 \pm 1.95$ individuals $\mathrm{m}^{-2}$ (mean \pm s.d., $n=24$ ), the counts of the soil probes $0.33 \pm 0.14$ individuals $0.125 \mathrm{~m}^{-2}$ (mean \pm s.d., $n=72$ ). Thus, our calculated population density is $6.89 \pm 3.09$ individuals $\mathrm{m}^{-2}$ (mean \pm s.d.). As the entire area of contiguous suitable habitat is approximately $40000 \mathrm{~m}^{2}$, the estimated total population size is $2.75 \pm 1.2 \times 10^{5}$ individuals. During our mark-recapture experiments, $2.47 \pm 0.75$ individuals $\mathrm{m}^{-2}$ (mean \pm s.d., $n=630$ ) were found alive on the surface on average. The index of dispersion varied only slightly throughout the year $\left(I_{D}=0.976 \pm 0.15\right.$ (mean \pm s.d., $n=14$ )). An aggregation of snails larger than the grid unit of $1 \mathrm{~m}^{2}$ could at no time be detected. The spatial distribution of $T$. geyeri can thus be assumed to be close to a random distribution.

Estimates for neighbourhood sizes range between 70 and 208 individuals (see table 1 ). The estimated size of a neighbourhood area ranges from $13 \mathrm{~m}^{2}$ to $21 \mathrm{~m}^{2}$.

\section{(b) Indirect method}

Application of 5 primers resulted in a total of 137 markers, 126 of which were polymorphic. All indi-
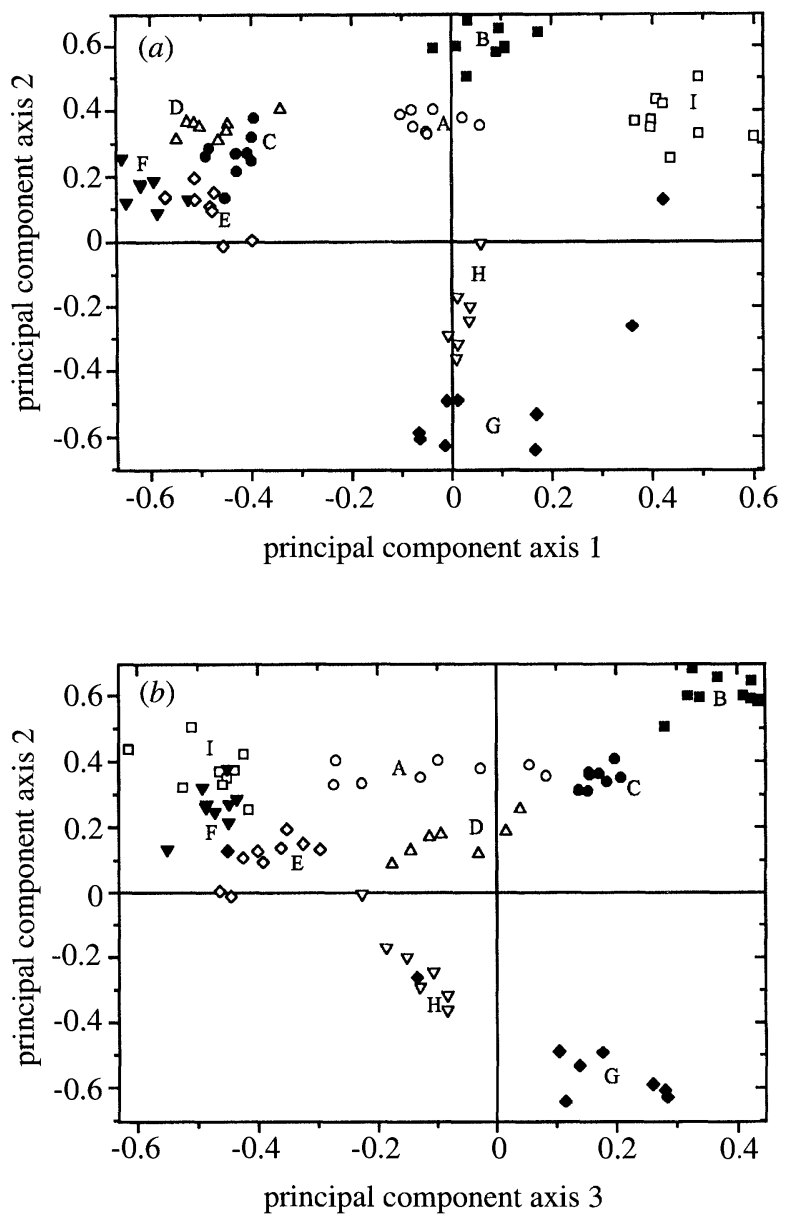

Figure 2. Principal component analysis of the RAPD data. (a) Plot of principal component axis 1 against principal component axis 2. (b) Plot of principal component axis 3 against principal component axis 2. Open circles: sampling site A; filled squares : sampling site B; filled circles : sampling site $\mathrm{C}$; open triangle peak up: sampling site $\mathrm{D}$; open rhombus: sampling site $\mathrm{E}$; filled triangle peak down: sampling site $\mathrm{F}$; filled rhombus: sampling site $\mathrm{G}$; open triangle peak down: sampling site $\mathrm{H}$; open squares : sampling site I.

viduals could be distinguished by their unique multilocus RAPD pattern. The bands were highly reproducible in the sense that the pattern produced was identical to former amplifications. In the rare cases of amplification failure, the RAPD procedure for this individual was repeated. Thus, we have reproduced each pattern at least twice for two template-DNA concentrations.

The first three principal components account for $16.4 \%, 14.9 \%$ and $12.6 \%$ of the total variation in the

Table 1. Results of direct estimation of population genetic structure: estimated neighbourhood sizes

(Variance of dispersal along a single axis is given for 120 and $150 \mathrm{~d}$.)

\begin{tabular}{llll}
\hline & & $\begin{array}{l}\text { density } \\
\left.\text { (individuals } / \mathrm{m}^{-2}\right)\end{array}$ \\
$\begin{array}{l}\text { variance of dispersal along } \\
\text { single axis }\end{array}$ & $\begin{array}{l}d=3.8 \mathrm{~m}^{-2} \\
(\text { mean }- \text { s.d.) }\end{array}$ & $\begin{array}{l}d=6.89 \mathrm{~m}^{-2} \\
(\text { mean })\end{array}$ & $\begin{array}{l}d=9.98 \mathrm{~m}^{-2} \\
\text { (mean }+ \text { s.d.) }\end{array}$ \\
\hline $0.5 \sigma^{2}{ }^{200 d}=1.471 \mathrm{~m}^{2}$ & 70 & 127 & 184 \\
$0.5 \sigma^{2}{ }_{150 d}=1.665 \mathrm{~m}^{2}$ & 80 & 144 & 208 \\
\hline
\end{tabular}


(d.f. = degrees of freedom; sSD = sums of squared deviations; MSD $=$ mean squared deviation; probability $p$ was calculated from 9999 permutations (see $§ 2$ for details).)

\begin{tabular}{lrrrllll}
\hline source of variation & d.f. & SSD & \multicolumn{1}{c}{ MSD } & $\begin{array}{l}\text { variance } \\
\text { component }\end{array}$ & $\begin{array}{l}\% \text { of } \\
\text { variance }\end{array}$ & $p$ & $\phi_{\mathrm{NT}}$ \\
\hline among sampling sites & 8 & 910 & 113.8 & 12.4 & 53.5 & $<0.0001$ & 0.535 \\
within sampling sites & 66 & 711 & 10.8 & 10.8 & 46.5 & $<0.0001$ & \\
\hline
\end{tabular}

presence-absence matrix. Among the other 71 principal components greater than zero, none accounted for more than $8.9 \%$ of variation. The gap between principal components 3 and 4 indicates that the first three components represent the most important 'dimensions' in the data. Overall, the PGA indicates that a substantial amount of genetic variation is attributable to geographic structuring, thereby reflecting the geographic relations of the sampling sites along the principal component axes. Axis 1 separates the sampling sites in east-west direction, whereas axis 2 distinguishes the sites rather in north-south direction. The sampling sites $\mathrm{C}, \mathrm{D}, \mathrm{E}$ and $\mathrm{F}$, forming a wide crescent, are separated along axis 3 (figure $2 a, b$ ).

Partition of molecular variance was tested on two hierarchical levels: among the individuals within sampling sites and among sampling sites within the total population. Our results indicate that more than half $(53.5 \%)$ of the total variance is attributable to the variance between sampling sites. The randomization procedure (number of permutations used: 9999) exhibits the high significance of the variance components and the $\phi$-statistic (see table 2). Bartlett's statistic indicates that the sampling sites do not differ significantly with respect to their variances within sampling site $(\chi 2=4.68$; d.f. $=8 ; p$ random Bartlett's statistic $>$ observed statistic $=0.0001)$. The two geographically closest sampling sites (B and C, $18 \mathrm{~m}$ apart) could be clearly separated when subjected to an AMOVA alone $(59.2 \%$ among $\mathrm{B}$ and $\mathrm{C}, p<0.0001)$.

Genetic distance increases significantly with geographic distance, despite the strong variation of euclidean distances within sampling sites (Mantel test; $r=0.567, p$ random $r>$ observed $r=0.0001$ ). Within sampling site $\mathrm{B}$, no significant increase of genetic distance with geographic distance could be observed $(r$ $=0.071, p$ random $r>$ observed $r=0.3499$ ).

\section{DISGUSSION}

\section{(a) Direct method}

Usually, not all snails present in an area are active on the surface, even under favourable weather conditions (Baur 1993). This general observation is supported by our finding that average density estimated by mark-recapture techniques is always lower than by thorough but destructive searching. The recovery rate in the mark-recapture experiments is correspondingly low, as previously reported by Cain \& Currey (1968) for Cepaea nemoralis. Thus, we used only the quadrat counts for estimation of population density. The low recovery rate prevents keeping track of a sufficient number of individuals through their entire lifetime. The dispersal data presented nevertheless reflect the locomotory activity over one complete lifetime period, thereby integrating weatherdependent periods of both high and low locomotory activity. Our estimated values may be overestimates of dispersal, as snails that were buried in the soil without locomotory activity might be underrepresented in the mark-recapture data. However, even a $50 \%$ increase in the frequency of movements under $1 \mathrm{~m}$ per $15 \mathrm{~d}$ does not substantially alter estimates of mean dispersal and assigned variances in our simulations (data not shown). The estimation of dispersal over longer periods for land snails by computer simulation appears to be a useful approach that has been successfully applied before by Baur \& Baur (1993). These authors could show that simulated dispersal of Arianta arbustorum (Helicidae) was comparable to distances actually dispersed in the field.

The density of $T$. geyeri is low compared with other helicid species (Greenwood 1974; Crook 1980; Cowie 1984). Obtaining estimates of absolute density, including the snails buried in the soil, is difficult, because habitat destruction is inevitable and can therefore not be applied extensively in a sensitive habitat. Consequently, we present estimates of neighbourhood size based on a relatively broad range of densities. These estimates may as well represent actual heterogeneity in density over the entire vineyard.

Estimates of neighbourhood size $N$ or effective neighbourhood size $N_{e}$ are available for only a few other helicid species. Neighbourhood size for Cepaea nemoralis ranges from 95 to 6000 (Greenwood 1974), for Theba pisana from 115 to 4130 (Cowie 1984), 15 to 215 for Helix aspersa (Crook 1980) and 5600 for Arianta arbustorum (Baur 1993). Most estimates, except those for $H$. aspersa, by far exceed the range of 70 to 208 reported here.

\section{(b) Indirect method}

None of the previous studies on neighbourhood population structure used high-resolution DNA markers for the indirect analysis of population structure. We applied RAPD marker (Williams et al. 1990) for the estimation of population genetic structure. The RAPD method is especially reliable for intraspecific and intrapopulation comparisons (Rieseberg 1996). Although RAPD markers are usually dominant and thus can not distinguish the homo- and heterozygous states for band presence (Clark \& Lanigan 1993), RAPDS usually reveal the same overall pattern of genetic 
structure when compared with allozymes (see, for example, Baruffi et al. 1995; Peakall et al. 1995). Moreover, RAPDs are reported to detect more genetic variation among individuals than allozymes (Liu \& Furnier 1993; Peakall et al. 1995). This might be attributable to the fact that the number and kind of loci revealed by RAPD analysis comprise a more complete sample of the genome than allozymes can provide. RAPDs are especially suitable markers for detection of minor changes in genetic composition, as expected under the neighbourhood model.

The principal component analysis revealed clines of genetic variation in different spatial directions. The ordination of individuals along the PCA axes is caused by the presence or absence of intercorrelated bands that represent allelic states of the corresponding loci. As each of the first three axes achieves an ordination that reproduces the geographic interrelations of the sampling sites with respect to one spatial direction, it is likely that each axis may reflect clines of allelic frequency changes of the loci involved along this spatial direction. This view is supported by the fact that the first three principal components account for a comparable amount of variation, representing clines over geographic distances of almost equal length. It seems that PGA is able to extract information about clines in allelic composition from RAPD data that can be gained otherwise only with codominant markers. This interpretation is in accordance with the isolation by distance concept that predicts a gradual change in genetic composition in all directions in continuously distributed populations (Wright 1951). The pattern we found would probably be even more pronounced if the sampling sites were chosen along linear transects across the population.

A considerable degree of populational structure caused by the variation between sampling sites could also be detected by AMOVA $(53.5 \%$ of the total variance). The high $\phi_{\mathrm{NT}}$ coefficient and variance homogeneity of within-sampling-site genetic distances suggests that sampling was done within neighbourhoods for all sampling sites, hence, neighbourhood size is at least not smaller than estimated from markrecapture experiments. This interpretation is supported by the fact that no isolation by distance could be found within sampling site $B$, suggesting random mating within this area. Moreover, the comparison among the two geographically closest sampling sites indicates that the size of neighbourhoods is not substantially larger than estimated $\left(13-21 \mathrm{~m}^{2}\right)$ from the direct approach. The closest sampling points B and C could clearly be distinguished by AMOVA, and the euclidean distances between individuals from each site are distinctly greater than between individuals within each site (data not shown). The level at which divergence starts to increase with distance can be considered as the boundary of neighbourhoods (Slatkin 1993). Here, this effect can be observed at a distance of $13-14 \mathrm{~m}$; 2.5-3.5 times greater than the diameter of an estimated neighbourhood area $(4-5.2 \mathrm{~m})$.

A highly significant overall pattern of isolation by distance in the investigated population could be observed when tested according to Mantel (1967). The not particularly high $r$-value, resulting from a scatter around the linear regression line, might be caused by slightly different rates of increase of genetic distance in different spatial directions because of heterogeneity in population densities. We found a similar pattern of genetic population structure by RAPD analysis in a smaller population of $T$. geyeri, but with a much smaller number of individuals (Mantel test: $r=0.84 ; p$ $=0.0066 ; N=18$; unpublished results).

\section{GONGLUSIONS}

Our results derived from direct and indirect methods are in general agreement. The estimates of populational subdivision from the direct method predict an isolation by distance structure within the population, which could be confirmed by the molecular genetic analysis. The amount of variation in RAPD data because of the gradual geographic change in genetic composition indicates that most of the genetic variation can be explained by dispersal-limited gene flow within the continuous population of $T$. geyeri. We have no information whether selfing occurs in $T$. geyeri. This reproductive mode can not be excluded a priori in simultaneously hermaphrodite snails (Jarne \& Städler 1995), but because outcrossing seems to be predominating in Helicidae (Selander \& Ochman 1983), we have not considered this situation. Furthermore, our findings achieved from the indirect method are in concordance with expectations for a neighbourhood structure of randomly mating hermaphrodites (Wright 1951). Moreover, taking into account that almost half $(46.5 \%)$ of the RAPD variation observed can be attributed to inter-individual differences within sampling sites, we conclude that selfing is unlikely to be the predominant reproductive mode in this population of $T$. geyeri. Corroborating evidence arises from the observation that $T$. geyeri has not reproduced when kept isolated, whereas it does when reared in groups (M. Pfenninger, unpublished results).

Passive dispersal, e.g. mediated by birds, grazing animals or human activities, has not been observed and has obviously not played a principal role in shaping the genetic structure of this population in the past, as inferred from the indirect analysis.

As this is the first study employing a closely integrated approach of both direct and indirect methods that reports an isolation by distance structure in land gastropods in a two dimensional habitat, comparisons with other studies are difficult. Selander \& Kaufman (1975) estimated the diameter of a neighbourhood of Helix aspersa to be about $30 \mathrm{~m}$, using allozymes. This indirect estimation is not in accordance with the direct estimation of 2.3-3.8 m provided by Crook (1980), but the studies were conducted in different populations. Arter (1990) found a pattern of a functional isolation by distance along the migration paths in alpine populations of Arianta arbustorum. Johnson \& Black (1995) could show a neighbourhood population structure with both direct and indirect methods in a littorine gastropod Bembicium vittatum along a linear shoreline habitat. However, they found a discrepancy between the estimates of direct and 
indirect methods that they attributed to occasional long range dispersal. All studies mentioned found these patterns on a spatial scale at least ten times larger than reported here. A study of population structure using RAPD marker in a snail of comparable size and ecology, Candidula unifasciata (Bahl et al. 1996) showed an isolation by distance structure on a scale similar to the one found in $T$. geyeri. The similarity in appearance and ecology may allow to transfer our results to other small land snail species (Magnin 1991; Bahl et al. 1996).

Our results indicate that a neighbourhood population structure, created by the process of randomly directed dispersal with limited range, might be one of the most important forces generating and maintaining genetic variability in continuously distributed populations of small land snails. Again, genetic variability is the indispensable basis on which micro- and macroevolutionary processes act.

We thank Thomas Städler and three anonymous referees for helpful comments that improved the manuscript. Christine Ott and Jörg Kreutz gave valuable help in fieldwork assistance. This study was supported by the BMBF (FKZ 0339523A).

\section{REFERENCES}

Arter, H. E. 1990 Spatial relationship and gene flow paths between populations of the alpine snail Arianta arbustorum (Pulmonata: Helicidae). Evolution 44, 966-980.

Bahl, A. \& Pfenninger, M. 1996 A rapid method for isolation of DNA using laundry detergent. Nucleic Acids Res. 24, 1587-1588.

Bahl, A., Pfenninger, M., Bamberger, H., Frye, M. \& Streit, B. 1996 Survival of snails in fragmented landscapes. In Species survival in fragmented landscapes (ed. J. Settle, C. Margules, P. Poschlod \& K. Henle). Amsterdam: Kluwer. (In the press.)

Baruffi, L., Damiani, G. \& Guglielmino, C. R. 1995 Polymorphisms within and between populations of Ceratitis capitata: comparison between RAPD and multilocus enzyme electrophoresis data. Heredity 74, 425-437.

Baur, A. \& Baur, B. 1993 Daily movement patterns and dispersal in the land snail Arianta arbustorum. Malacologia 35, $89-98$.

Baur, B. 1993 Population structure, density, dispersal and neighbourhood size in Arianta arbustorum (Linnaeus 1758) (Pulmonata: Helicidae). Annalen des Naturhistorischen Museums Wien 94/94B, 307-321.

Bowen, B. W., Meylan, A. B., Ross, P. J., Limpus, C. J., Balazs, G. H. \& Avise, J. C. 1992 Global population structure and natural history of the green turtle (Chelonia mydas) in terms of matriarchal phylogeny. Evolution 46, 865-881.

Cain, A. J. \& Currey, J. D. 1968 Studies on Cepaea. III. Ecogenetics of a population of Cepaea nemoralis (L.) subject to strong area effects. Phil Trans. R. Soc. Lond. B 253, 447-482.

Castillo, R. F. del. 1994 Factors influencing the genetic structure of Phacelia dubia, a species with a seed bank and large fluctuations in population size. Heredity 72, 446-458.

Clark, A. G. \& Lanigan, C. M. S. 1993 Prospects for estimating nucleotide divergence with RAPDs. Molec. Biol. Evol. 10, 1096-1111.

Cowie, R. H. 1984 Density, dispersal and neighbourhood size in the land snail Theba pisana. Heredity 52, 391-401.
Crook, S. J. 1980 Studies on the ecological genetics of Helix aspersa (Müller). Ph. D. Thesis, University of Dundee.

Eguiarte, L. E., Burquez, A. \& Rodriguez, J. 1993 Direct and indirect estimates of neighbourhood and effective population size in a tropical palm, Astrocaryum mexicanum. Evolution 47, 75-87.

Excoffier, L., Smouse, P. E. \& Quattro, J. M. 1992 Analysis of molecular variance from metric distances among DNA haplotypes: application to human mitochondrial DNA restriction data. Genetics 131, 479-491.

Greenwood, J. J. D. 1974 Effective population numbers in the snail Cepaea nemoralis. Evolution 28, 513-526.

Greenwood, J. J. D. 1976 Effective population number in Cepaea: a modification. Evolution 30, 186.

Iwao, S. 1972 Application of the m-m method to the analysis of spatial patterns by changing the quadrat size. Res. pop. Ecol. Kyoto 14, 97-128.

Jarne, P. \& Städler, T. 1995 Population genetic structure and mating system evolution in freshwater pulmonates. Experientia 51, 482-497.

Johnson, M. S. \& Black, R. 1995 Neighbourhood size and the importance of barriers to gene flow in an intertidal snail. Heredity 75, 142-154.

Lacy, R. C. 1987 Loss of genetic diversity from managed populations: interacting effects of drift, mutation, immigration, selection and population subdivision. Cons. Biol. 1, 143-158.

Lewontin, R. C. 1974 The genetic basis of evolutionary change. New York: Columbia University Press.

Liu, Z. \& Furnier, G. R. 1993 Comparison of allozyme, RFLP, and RAPD markers for revealing genetic variation within and between trembling aspen and bigtooth aspen. Theor. appl. Genet. 86, 97-105.

Magnin, F. 1991 Mollusques continentaux et histoire quaternaire des milieux mediterraneens. Ph.D. thesis, Université d'AixMarseille II.

Manly, B. F. J. 1994 Multivariate statistical methods: A primer, 2nd edn. London: Chapman \& Hall.

Mantel, N. 1967 The detection of disease clustering and a generalised regression approach. Cancer Res. 27, 209-220.

Peakall, R., Smouse, P. E. \& Huff, D. R. 1995 Evolutionary implications of allozyme and RAPD variation in diploid populations of dioecious buffalograss Buchlö dactyloides. Molec. Ecol. 4, 135-147.

Pfenninger, M. \& Bahl, A. 1995 Die Bedeutung von Habitatqualität und Isolation für genetische und demographische Parameter von Trochoidea geyeri. Verhand. Gesell. Ökol. 24, 215-218.

Pfenninger, M., Frye, M., Bahl, A. \& Streit, B. 1995 Discrimination of three conchologically similar Helicellinae (Helicella, Gastropoda) species using RAPDfingerprinting. Molec. Ecol. 4, 521-522.

Pielou, E. C. 1969 Mathematical ecology. New York: John Wiley \& Sons.

Rieseberg, L. H. 1996 Homology among RAPD fragments in interspecific comparisons. Molec. Ecol. 5, 99-105.

Schilthuizen, M. \& Lombaerts, M. 1994 Population structure and levels of gene flow in the mediterranean land snail Albinaria corrugata (Pulmonata: Clausiliidae). Evolution 48, 577-586.

Selander, R. K. \& Kaufman, D. W. 1975 Genetic population structure and breeding systems. Isozymes 4, 145-167.

Selander, R. K. \& Ochman, H. 1983 The genetic structure of populations as illustrated by molluscs. Isozymes $\mathbf{1 0}$, 93-123.

Slatkin, M. 1987 Gene flow and the geographic structure of natural populations. Science, Wash. 236, 787-792.

Slatkin, M. 1993 Isolation by distance in equilibrium and non-equilibrium populations. Evolution 47, 264-279. 
Southwood, T. R. E. 1978 Ecological methods, with particular reference to the study of insect populations, 2nd edn. London: Chapman \& Hall.

Williams, J. G. K., Kubelik, A. R., Livak, K. J., Rafalski, J. A. \& Tingey, S. V. 1990 DNA polymorphisms amplified by arbitrary primers are useful as genetic markers. Nucleic Acids Res. 18, 6531-6535.

Wright, S. 1932 The roles of mutation, inbreeding, crossbreeding and selection in evolution. Proc.VI. Intl. Congr. Genet. 1, 356-366.
Wright, S. 1946 Isolation by distance under diverse systems of mating. Genetics 31, 39-59.

Wright, S. 1951 The genetical structure of populations. Ann. Eugen. 15, 323-354.

Wright, S. 1978 Evolution and the genetics of populations vol. 4. Variability within and among natural populations. University of Chicago Press.

Received 22 April 1996; accepted 10 June 1996 